This is an open access article under the CC BY-NC-ND license (https://creativecommons.org/licenses/by-nc-nd/3.0/) Issue II, November 2019

ISBN 978-601-323-144-0

https://doi.org/10.31643/2019.004

\author{
Mariam Ravilievna Arpentieva \\ Tsiolkovskiy Kaluga State University, Russia \\ E-mail: mariam_rav@mail.ru \\ ORCID ID 0000-0003-3249-4941
}

\author{
Olzhas Kenzhaliyev \\ Satbayev University, Kazakhstan \\ E-mail: olzhas.kenzhaliyev@gmail.com \\ ORCID ID 0000-0002-3776-9724
}

\author{
Gulzhaina Kassymova \\ Abai Kazakh National Pedagogical University \\ E-mail: zhaina.kassym@gmail.com \\ ORCID ID 0000-0001-7004-3864
}

\author{
Heri Retnawati \\ Yogyakarta State University, Indonesia \\ E-mail: heri_retnawati@uny.ac.id \\ ORCID ID 0000-0002-1792-5873
}

\author{
Aigerim Kosherbayeva \\ Abai Kazakh National Pedagogical University \\ E-mail: aigera63@mail.ru \\ ORCID ID 0000-0002-3307-9814
}

\title{
Intersubjective Management in Educational Economy
}

Summary. The modern economy, the management of its development, is one of the most actively developing aspects of the life of the community, closely related to others (cultural and ideological, political and historical, psychological and legal transformations.) Recently, researchers are seeking answers to questions of optimizing the development of the economy in theories and technologies not only monoagent and multi-agent control, but monoactor and multi-agent, quality and quantity management, logistics and production processes, management real-time management of strategic crisis management. All of them require the coordination of opinions and interests of various stakeholders in the context of specific internal and external conditions of their life. The successful implementation of innovation and non-destructive interaction with the community require economic and related structures and organizations to build partnerships. These relations should take into account the need to take care of the accumulation and deterioration of not only financial and material, but also social, human and cultural capital proper, work with cadres and consumers, and so on. This article presents a postnonclassical approach to create the science of management processes organization in a developing society, the focus of which is "the man of culture", i.e. the man, not just adhering to cultural norms, but also creating new concepts and products of culture. This science is proposed to be called Evergetics. This science was determine as the science of management processes organization in a developing and other industrial areas of society, each member of which is interested in augmenting his cultural heritage he is producing. It is entails a raise of cultural potential of the society as a whole and, as a consequence, an increase in the proportion of moral and ethical managerial decisions and corresponding to them benevolent actions in public life. Intersubjective management is a leading aspect of the development of the dynamic (cap)abilities of educational enterprises in general and managers of these enterprises in particular. The foresight for managing the educational economy should first of all be addressed to the capabilities of multi-actor management. Multi-actor management allows you to systematically, and not unilaterally, take into account all aspects of the educational institution and the entire network of institutions, including economic issues.

Kewwords: management; developing society, economy, education, Evergetics; intersubjective technologies, crowd-technologies, dynamic (cap)abilities.

Introduction. The modern educational economy, the management of its development and development of the educational industry in whole, is one of the most actively developing aspects of the life of the community, closely related to others (cultural and ideological, political and historical, psychological and legal transformations) spheres (Baymatov, 2017; Borisova, Kiseleva , 2016; Vasilyeva, Semakina, 2017; Wallershtain, 1995). Recently, researchers are seeking answers to questions of optimizing the development of the educational economy in theories and technologies not only monoagent and multi-agent control, but monoactor and multi-agent, quality and quantity management, logistics and production processes, management real-time management of strategic crisis management. All of them require the coordination of opinions and interests of various stakeholders of the education as the industry and as the cultural 
phenomenon in the context of specific internal and external conditions of their life. The successful implementation of innovation and non-destructive interaction with the community require economic and related structures and educational organizations to build partnerships, responsible, personified / individualized relationships (Samkov, Shvetsov, 2017). These relations should take into account the need to take care of the accumulation and deterioration of not only financial and material, but also social, human and cultural capital proper, work with cadres and consumers, and so on. In modern science and management practices and improve the management of regions and the country leading points are the points related to the achievement of sustainable, stable development, thus the basic issue of state and regional governance - the issue of optimization of its technologies (including economical technologies).

Aim of the study. The purpose of the study is an analysis of the prospects and difficulties of implementation of intersubjective technology in the modern educational economy (Baymatov, 2017; Vasilyeva, Semakina, 2017; Dzedik , 2017; Pryadko, 2016). The regional policy of sustainable social and economic development provides for the formation and development of the management reserve, the care of the personnel of industrial enterprises, the analysis of their main problems and resources, and the search for directions for their solution. The public and the state and business jointly ensure the security of their relations, relying on the imperatives of social responsibility, partnerships, the quality and efficiency of their activities. These imperatives prevent new ones and remove existing obstacles in the development of the educational and correlate with educational spheres of the economy, and other related with economy spheres in the context of globalization, intensive migrations and other processes of "re-mapping the world map," ethnic and other types of revival. (Tanshin, 2016; Ledeneva, Bubnova, 2017; Smetanina, Zhikina, Soboleva, 2016). In many respects the solution of problems of wear is connected with the construction and development of public-private partnerships in different regions of Russia and between regions for the implementation of socially significant projects. This will provide an opportunity to harmonize innovation and standardization, cyclical and revolutionary transformation of the economy and other spheres (Samkov, Shvetsov , 2017; Smetanina., Soboleva, 2017; Chernov, Sukhanov, 2016).

Materials and Methods. The main method of research is the theoretical analysis of the problems of government and education as industry (including economics) in the modern world. Special attention is paid to the concepts of crowd-management and evergetics, as well as intersubjective technologies, differences from monosubjective technologies in educational economy.

Results. The crisis of educational economy in the modern world and states as whole demonstrates that the classical and post-classical model of management in education and culture in whole obsolete. The modern model of government and communities is being developed in Evergetics. Evergetics is the science of intersubjective management, qualitatively different from the management of bureaucratic, monosubject (Arpentieva, 2015; Arpentieva, 2016; Vittikh, 2015b), which explicitly seeks globalization and mondialisation (merge countries in the universal state with a single control, the exception is «public opinion» from the Department of state) and, less explicitly, corporate (split governance within each country and throughout the world under the «power of crowds» transfer of control «public opinion»). Evergetics, in contrast to the classical and non-classical theories of management, guidelines which serve as corporate, suggests a number of changes. Its calling attention to the importance of cooperation. This cooperation based on the opinions of all parties concerned in a particular decision of people. The essential movable clustering of communities and systems, which traditionally controls the «monolith system» (bureaucracy), restoring relationships «horizontal», need cooperation at different levels and functions of the agencies and organizations as cooperation and mutual support of people in the different structures in the solution of specific (groups of) problems and the strengthening of local self-government (grassroots level). It is necessary to organize the cooperation of professionals and non-professionals. It is necessary to organize the cooperation as the heterogeneous actors systems. These systems have different points of view and values; it is important attention to the processes of self-development and mutual development of economic and other systems: society, state and the man himself. This is a complex, heterogeneous, lowrarchy, developing system, each component which interprets itself in dialogue with others in «the kaleidoscope of situations», more or less important for them, representative government determines Executive.

Discussion. The solution of the problem of the successful forecasting of the development of the educational and other spheres of the economy and production (including the functioning and improvement of various industrial markets) in a crisis period for the Russian community and its economy in whole was 
inextricably link with the prevention of exhaustion and the intensive development of the dynamic abilities of cultural and educational enterprises (theirs's financial and industrial spheres). It was connect with the abilities and readiness of the educational firms and markets to restructure and reorient their life: diversify in the context of the main, trend lines of regional and national markets in different sectors of the national economy and business. For this, enterprises should be able to distinguish and develop not only "strong", easily visible, but also relatively "weak", subtle, but no less significant trends and changes. Educational organizations and firms need to be able to identify and effectively respond to the main and possible threats and prospects for expansion and other forms of enterprise development in the sectoral and temporal contexts. Educational firms need to be able to identify and effectively respond to the main and possible threats and prospects for expansion and other forms of enterprise development in the sectoral and temporal contexts. Strategic management in our country at the beginning of the 21 st century was clearly aime at comparing the retrospective and perspective aspects of its life activity. It involves a comprehensive analysis of old and new sources of evolution and involution, constraints and production possibilities in accordance with the challenges of specific time and space. It also includes the analysis of regional requests, the prevention and correction of crises and collapse at the organizational and regional level, the reduction and denorming of bureaucratization and corruption in state and other spheres of activity, reducing the "leakage of personnel" and "brain drain", removing downshifting phenomena as a conscious refusal and deprofessionalization, increasing the trend of "up-up" as a service and participation. Such management in the sphere of economy and production proceeds from the notion that in the world all events and phenomena were inextricably link with each other. Thus, even the most "negative", destructive aspects of life, relations and events can either be realized and corrected, or carry a "positive" function that needs to be revealed and implemented. So, can and should be identified and activated, and in some cases, purposefully formed and developed phenomena and events that form the conditions for the transition of production and the economy, as well as society as a whole to a new level. In this connection, the role of awareness and development of such dynamic abilities of financial and industrial enterprises that allow to identify and predict changes in the life of the industry and enterprises is growing. They should also allow long-term and targeted (strategic) planning based on this forecast, their conclusions about future more or less important and "trends" that lie in the line of "trends," to manage these and less obvious, albeit no less significant changes. In this sense, the concept of the dynamic capabilities of enterprises adjoins the theory of foresight, as well as a number of other theories and models developed in the context of the concept of complex systems.

We need focuses on the D. J. Teece dynamic capabilities theory, foresight theory and on the V.A. Vittikh multy-actors management theory.

D. J. Teece (2007) proposed an elaborated framework consisting of three factors; sensing, seizing, and reconfiguring. Dynamic capabilities can usefully be thought of as belonging to three clusters of activities and adjustments: (1) identification and assessment of an opportunity (sensing); (2) mobilization of resources to address an opportunity and to capture value from doing so (seizing); and (3) continued renewal (transforming). These activities are required if the firm is to sustain itself as markets and technologies change, although some firms will be stronger than others in performing some or all of these tasks. Reconfiguration requires the company to maintain strong leadership, business model redesign and assetrealignment activities. Sensing is the main foresight competence (capability) component. Foresight is a system of methods of transformation of priorities in the sphere of economy and production, social and cultural development .

Analysis of foresight competence as a component of dynamic capabilities (competences) of the financial and production organizations shows their leading role in the implementation of other dynamic capabilities. Its shows the fact that foresight enterprises and industries is having a transformative impact on the development of the system, helping to transform and not just to predict the development of the industry or enterprise. Foresight involves the use and transformation meta-technology ("routines") of enterprise and innovation in the field of production and relations of production. It was aim at the allocation and use of markers of change - weak and strong signals of future and probable changes. Active and accurate identification of these markers changes, including application and modification of routine or metatechnology of enterprise management, not only allows to predict "unpredictable", but also to intervene in the process flow, correcting them with the least expenditure of forces, material, mental and spiritual resources. In addition, it allows you to influence the markets themselves and the surrounding enterprise reality in General. Thanks to the foresight competence and ability, the educational manager and his company productively adapt to changes in environment (market and society), but also participate in changing it.

V.A. Vittikh wrote that modern technologies of governance and industry include three options: bureaucracy, hierarchy, creating monoactor / «monolithic» control systems are widely used, demonstrating 
the inability to solve problems related to the management of such complex systems as man, society, state. Lowrarchy creating multifactorial management system can be used to solve problems that are difficult or impossible to solve by a single actor / $\gg$ monolithic system». Corporate or crowd-management supporting quasi-multi-actor system and simulates the intersubjectivity of making and implementing decisions, are used by the bureaucracy as an attempt to «change without changing» (Borisova, Kiseleva, 2016; Vasilyeva, Semakina, 2017; Wittih, Moiseeva, Skobelev, 2013; Vittikh, 2015b). The technology multi-actor / intersubjective management is radically different from the crowd-technologies (table 1). Evergetics is not based on «artificial» order, supported Monoactor management systems, but the natural orde. In traditional management, we are talking about deterministic systems: supported by artificial order, the reliance of managers on legal standards and destruction of legal norms (corruption, bureaucracy), formal hierarchy, proprietary, monologic information exchange and single-handedly solves the problem of the leader. People is a homogenous «herd» or "cattle». The consumerism as «the ideology of the gangster» stimulates the relations of type of slavery (the involution of humanity). «Universal recipes» of the classical management consideration of situations in all cases cause the system to collapse, the reduction of energy and information. Evergetics involves the management of self-developing systems: the head does not interfere with the natural order: unstructured group with the free, outwardly chaotic, Dialogic information exchange and collective decision-making.

Table 1. Technology intersubjective and crowd management

\begin{tabular}{l|lr}
\hline Crowd-technology & \multicolumn{1}{c}{$\begin{array}{c}\text { Technology intersubjective } \\
\text { management }\end{array}$} \\
\hline $\begin{array}{l}\text { Professionals are the members of } \\
\text { Professionals and } \\
\text { the «smart crowd». They can }\end{array}$ \\
participate in the isolation and (heterogeneous) actors involved \\
resolution of problems of different in taking the decision directly \\
levels, self-organization depending relating to their problems, the \\
on the need and the degree of main issue is the involvement of \\
involvement and expertise in the actors in the process of discussing \\
matter under discussion. The main and implementing decisions \\
question - treatment discussions of (personal responsibility). \\
crowd problems (processing of
\end{tabular}

information).

The decision taken by the head (quasi multi-actor technology, simulation of multiactivity /intersubjectivity); the use of mechanisms of total public control, involvement of citizens in relationships in which they are subjects (actors) and objects.

The power is fenced off from citizens with «system agents» for the processing the data of «public opinion» and other means to develop relations of control, increasingly destroying the boundaries of the individual and the organization, as well as prevent it from moral and legal imperatives of culture.
The decision implement actors (multi-actor, intersubjective technology) the involvement of citizens in the relations concerning the recognition of subjectivity and subjectivity, the ability to organize themselves.

The government establishes citizens of the real relations of cooperation, it is transparent, but does not require transparency from individuals and organizations, respecting their boundaries (within the marked moral and legal imperatives of culture).

People and situations are different, the mutual aid as the relationship of social service to allow humanity to evolve, there are no common recipes for all occasions, the discussion about each specific situation leads to an increase of energy and information.

The main change processes, therefore, involve

the growth of information and energy (the effect of dialogue or polylogue), other systems optimizations; 
$>$ restoration and development of culture as a system of moral and legal standards, harmony, inclusion and responsibility, transparency and respect (social and human capitals);

$>$ the activation of man, society, state, clustering and self-organization of society (actors and situations);

$>$ sustainable development of human society, the state, anty-crisis effects (smoothing and removal of the crises).

Economic and other system of the economy - changing process in which a Manager must account not only for «strong» and «weak signals», including the opinion and life of the «little» people. So instead, to achieve the ideal of «diligence» as «learned helplessness», it is important and necessary to maintain the willingness to give / sacrifice, respect people and government of the dignity of each other. Evergetics suggests that management reform and modernization of its structure includes a number of points:

- rethinking the role of the importance of human and social capital in the development of the state, society and its management ;

- the formation and application of management technologies, taking into account the «human factor»;

- the understanding of the importance of social partnership and cooperation of the «centre» and periphery, entrepreneurs and consumers, professionals and non-professionals;

- the development and application of technology cooperation /partnership, their activation;

- understanding of perspectives of relations of social service and mutual help, moral supports development;

- (trans)formation and application of technology focused on the development of the cultural capital of communities and organizations;

- de-liberalization of relations between the state, society and business the violation of moral norms, overcoming social anomie and social cannibalism;

- the decision of problems of social exclusion and lack of accountability: the growth of social inequality, unemployment and precarization of professional work;

- the solution to the problems of sustainable development: crises of individual and organizational development (professional deformation and downshifting to organizational collapse);

- the deformalization and dissimulatio of state support for its citizens and businesses, to fight corruption at the local level, the periphery of the (moral and legal);

- the creation of mechanisms to support socially responsible business and to encourage the participation of individuals and groups in the management of (moral and legal);

- the introduction of alternative forms of conflict resolution/decision-making (mediation) in health care, education, policing and other fields (Arpentieva, 2015; Arpentieva, 2016; Wallershtain, 1995; Vittikh, 2015a).

The basic principles of the reforms are as follows:

1. the ideology of the «moral fact that profitable,» ignoring the problems and opposition as the suppression of the riots are the society and the country to collapse;

2. the life - changing process that requires attention not only to the «strong» and «weak signals», including the opinion and life of the «little» people;

3. instead of «learnt helplessness», it is necessary to maintain and develop the willingness to give / sacrifice, respect people and government of the dignity of each other.

The mood on the ideals of social service:

1. the reconstruction problem of optimization and development of human communities and the moral foundations of their functioning, orientation to the strategic «benefits»;

2. the required acts of mercy and charity, as well as acts of joint activities of different organizations and people in search of moral forms of governance and of human life, the organization of the state;

3. restoration and development of culture (moral and legal regulator of relations of people and communities)

Modern management, however, often involves a number of completely opposite of the developmental, modernization, and phenomena:

1. ignoring the dissent, a lack of attention to social and human capital, giving birth to the deprofessionalization, downshifting professionals and managers in economy, as well as the turnover rate of organizational collapse; 
2. the production of disposable and/or known to be harmful to human, his mental and physical health goods and services, the crowding out of honest manufacturers and the exploitation of the baser instincts of the «crowd»;

3. the society is moving towards the ideology of consumption, increasing consumerism, more and more clearly understood neo-slavery nature of the relationship in many modern organizations, including the economy organizations, the rejection of the innovation or failure.

As noted by V. A. Wittih, «Each actor exists simultaneously in two worlds: in the life world (everyday life) and in the system worlds, where the man-actor turns into a depersonalized "element" of the system, interacting with other "elements" by the established rules. During the negotiations in everyday life, focused on finding a way to settle the situation which should satisfy everybody, heterogeneous actors, acting as "practicing social theorists" or "ordinary sociologists", have to reach a mutual understanding and consensus on the choice of value priorities that will provide an opportunity to formulate the objectives, criteria, restrictions and, ultimately, the problems demanding their solution in the formally organized system world, which is studied by classical science» (Vittikh, 2015c: 949). He believes that «the Evergetics, returning the language of science in everyday life, is created as a value-oriented science that answers the question "what for to do?" and "what to do", while the traditional management science seeks to answer the question "how it should be done? (in the best way, whenever possible)". So, the Evergetics doesn't conflict with the classical management science, but is its necessary complement corresponding to postnonclassical stage of the science's development» (Vittikh, 2015c: 949).

Conclusions. Intersubjective management is a leading aspect of the development of the dynamic abilities of educational enterprises in general and managers of these enterprises in particular. The foresight for managing the educational economy should first of all be addressed to the capabilities of multi-actor management. Multi-actor management allows you to systematically, and not unilaterally, take into account all aspects of the educational institution and the entire network of institutions, including economic issues.

This article presents a postnonclassical approach to create the science of management processes organization in a developing society, the focus of which is "the man of culture". This science is proposed to be called Evergetics and determined as the science of management processes organization in a developing group, organizations and other society, each member of which is interested in augmenting his cultural heritage he is producing, which entails a raise of cultural potential of the society as a whole and, as a consequence, an increase in the proportion of moral and ethical managerial decisions and corresponding to them benevolent actions in public life (Vittikh, 2015a: 825).

Therefore, the movement to the new system of relations accompanied by a multi-level crisis. The lowrarchy as the management of «bottom-up», social service and interaction on the basis of the principles of the gift exchange complementing market and distribution relationships are hard to «restore» its position in the society and it's organizations.

As suggested by the Creator of the evergetics, «the theory of intersubjective management, based on postnonclassical scientific rationality and on concept of a free society, wherein the stake is made on nonviolent means of decision-making oriented towards attainment of mutual understanding and consensus of heterogeneous actors who are in a problem situation and aimed to settle it. The actors not only cognize the world, but they create it. When occurs that they are bound by a common problem situation, the actors, possessing, by their nature, intersubjective mind, realize it differently, although they recognize simultaneously the necessity of any coordinated actions to control the situation» (Vittikh, 2015b: 67). The truth as the result of a convention, an agreement was be achieve to recognize certain subjective knowledge to be true for a restricted circle of actors. Such knowledge been call as intersubjective. "In contrast to the bureaucratic theory that ignores individual qualities of the human being and sees it as a "cog" in the administrative mechanism, the theory of intersubjective management proceeds from the fact that the reserves of management efficiency rise should be sought not in the bureaucratic machine modernization, but in the human being, in every person, in the use of his intellectual and volitional resources» (Vittikh, 2015b: 67). Modern manager in economy and other spheres develops an understanding that the economy in General and manufacturing in particular is not reduced to «business», innovation and change of technological structures puts the center of production and other forms of relationships of the people themselves, social and human capital. It is important to understand that anti-crisis measures as developmental activities: therefore, the restoration of culture, including the moral foundations of the relationship - the main condition of success. Summing up, we note that the results of research in the field of intersubjective management technologies can 
and shell be use in the optimization of socio-political and economic relations in economy, in the transition from repressive management to the co-creative artistic and parity relationships.

Cite this article as: Arpentieva M.R., Kassymova G., Kenzhaliyev O., Retnawati H., Kosherbayeva A. (2019) Intersubjective Management in Educational Economy. Materials of International Practical Internet Conference "Challenges of Science". ISBN 978-601-323-1440. Issue II, 2019. Page 24- 31. https://doi.org/10.31643/2019.004

\section{References}

[1] Arpentieva, M. R. (2015) Evergetics strategies and development management communities //Proceedings of the XVII International conference "problems of control and modeling in complex systems», 22-25 June 2015, Samara. Samara: IPUSS RAS Publ.: 174-180.

[2] Arpentieva, M. Destruction of the University: from a "Comprehensively Developed Personality" to a "Robustly Robust Specialist” (Арпентьева, М. Разрушение университета: от «Всесторонне развитой личности» к «робото утойчивому специалисту»). Challenges of Science (In Russian), 2018. https://doi.org/10.31643/2018.002

[3] Arpentieva M. R. (2016) Intersubjective management technology// Problems of control and modeling in complex systems. Proceedings of the XVIII International conference. 20-25 September 2016, Samara, ed: E. A. Fedosov, N. Kuznetsov, V. A. Wittih. Samara: «ETCHING», Scientific Centre of RAS:39-52.

[4] Arpentieva, M. R., Kassymova, G. K., Lavrinenko, S. V., Tyumaseva, Z. I., Valeeva, G. V., Kenzhaliyev, O. B., Triyono, M. B., Duvalina, O. N., Kosov, A. V., Dossayeva, S. K. Environmental educationin the system of global and additional education. Bulletin of National Academy of Sciences of the Republic of Kazakhstan. ISSN 1991-3494. Volume 3, Number 379 (2019), p. 158 - 168. https://doi.org/10.32014/2019.2518-1467.82

[5] Baymatov A.A. (2017) Regional policy of sustainable socio-economic development. Business. Education. Right. Bulletin of the Volgograd Institute of Business, 1: 160-164.

[6] Borisova A.A., Kiseleva M.M. (2016) Management reserve: the methodology of formation and assessment of economic efficiency. Business. Education. Right. Bulletin of the Volgograd Institute of Business , 4 (37): 38-43.

[7] Chernov S.S., Sukhanov I.S. (2016) Questions of assessing the effectiveness of implementation of socially significant projects. Business. Education. Right. Bulletin of the Volgograd Institute of Business , 4 (37): 92-97.

[8] Dzedik V.A. (2017) Analysis of factors affecting the development of quality management systems. Business. Education. Right. Bulletin of the Volgograd Institute of Business , 1:175-179.

[9] Goncharov S.P. (2017) Teoretiko-legal research of a parity of a public order and public safety. Business. Education. Right. Bulletin of the Volgograd Institute of Business: 254-258.

[10] Kassymova, K. G., Aksarina, I. Y., Demchuk, A. V., Stepanova, G. A., Aksarina, Y. S. Bogach M. A., Brovkina S. N., Kosov A. V., Arpentieva M. R., Dossayeva S. K. (2019). Foresight and the role of innovation in the development of education. Bulletin of National Academy of Sciences of the Republic of Kazakhstan. ISSN 1991-3494. 4(380), 93-101. https://doi.org/10.32014/2019.2518-1467.96

[11] Ledeneva M.V., Bubnova Yu.S. (2017) The Consequences of Globalization for Developed and Developing Countries in the World. Business. Education. Right. Bulletin of the Volgograd Institute of Business: 146-149.

[12] Pryadko I.A. (2016) The concept of development of public-private partnerships in the regions of Russia. Business. Education. Right. Bulletin of the Volgograd Institute of Business, 4 (37):176-181.

[13] Samkov T.L., Shvetsov Ya.P. (2017) On some problems in the construction of agent-oriented models of economic processes. Business. Education. Right. Bulletin of the Volgograd Institute of Business , 4 (37): 85-87.

[14] Smetanina T.V., Soboleva M.G. (2017) Elements of innovative development of the organization by stages of its life cycle. Business. Education. Right. Bulletin of the Volgograd Institute of Business: 187-191.

[15] Smetanina T.V., Zhikina O.V., Soboleva M.G. (2016) Interrelation of the concepts of innovation, cyclicity and standardization. Business. Education. Right. Bulletin of the Volgograd Institute of Business, 4 (37):75-80.

[16] Tanshin V.V. (2016) Evaluation of companies in the field of social responsibility of business. Business. Education. Right. Bulletin of the Volgograd Institute of Business, 4 (37): 44-50.

[17] Teece, D.J. (2007). "Explicating Dynamic Capabilities: The Nature and Microfoundations of (Sustainable) Enterprise Performance". Strategic Management Journal. 28 (13): 1319-1350. https://doi.org/10.1002/smj.640

[18] Vasilyeva M.V., Semakina G.A. (2017) Staffing of industrial enterprises: the main problems and directions of their solution. Business. Education. Right. Bulletin of the Volgograd Institute of Business, 44-46.

[19] Vittikh V.A. (2015a) Evolution of Ideas on Management Processes in the Society: From Cybernetics to Evergetics, Group Decision and Negotiation, 2024: 825-832. https://doi.org/10.1007/s10726-014-9414-6

[20] Vittikh V.A. (2015b). Introduction to the Theory of Intersubjective Management. Group Decision and Negotiation, 24: 6795. https://doi.org/10.1007/s10726-014-9380-z

[21] Vittikh. V.A. (2015c) Heterogeneous Actor and Everyday Life as Key Concepts of Evergetics. Group Decision and Negotiation, 24: 949-956. https://doi.org/10.1007/s10726-014-9423-5

[22] Wallerstein I. (1995) After liberalism. New York: New Press: 1-288.

[23] Wittih V. A., Moiseeva, T. V., Skobelev P. O. (2013) A decision-Making based on consensus with the use of multi-agent technology. Ontology engineering, 2(8): 20-25. 